Didáctica. Lengua y literatura

ISSN: 1130-0531

http://dx.doi.org/10.5209/DIDA.57141

\title{
La violencia de género en el aula de literatura. Un proyecto por la sensibilización con la violencia de género en el aula de literatura a través de cuentos de Emilia Pardo Bazán
}

\author{
Alicia Romero López ${ }^{1}$
}

Recibido: 29 de septiembre de 2016 / Aceptado: 8 de julio de 2017

Resumen. La violencia de género es uno de los problemas sociales más importantes en la actualidad. Las leyes, a este respecto, han ido evolucionando paulatinamente para poder garantizar la integridad física y psicológica de las mujeres que sufren este tipo de violencia, sin embargo, los asesinatos y malos tratos se siguen sucediendo y, contra todo pronóstico, aumentando. Los últimos textos legales, tanto los que versan estrictamente sobre violencia de género así como los que regulan los diferentes niveles educativos, han incluido como un objetivo fundamental que la enseñanza funcione como un motor que construya valores igualitarios y que conciencie sobre la violencia de género. Para llevar a cabo este arduo trabajo consideramos que el aula de literatura debe ser una herramienta fundamental para el cambio social. El presente estudio presenta un proyecto didáctico, en el que a través de dos cuentos de Emilia Pardo Bazán, se trabaja no solo la crítica literaria, sino también la social, centrada en la concienciación sobre la violencia de género.

Palabras clave: violencia de género; literatura; igualdad; Emilia Pardo Bazán; educación.

\section{[en] Gender violence in the literature classroom. A project to raise awareness of gender-based violence through the tales of Emilia Pardo Bazán}

\begin{abstract}
Gender-based violence is one of the most important social issues in contemporary society. Legal responses to the phenomenon have gradually evolved to safeguard the physical and psychological wellbeing of women that are victims of such acts of aggression but instances of violence (including murder) continue to rise. Recent legislature has prioritised education as the vehicle through which core values such as equality and greater consciousness surrounding the issue can be constructed. In order for such values to become the norm we consider that the teaching of literature should be employed as a key tool in the move towards social change. Engaging not only with literary criticism but also broader social themes, this investigation presents a didactic project in which two of Emilia Pardo Bazán's short stories are approached as important documents in the building of this new consciousness surrounding gender-based aggression and violence.
\end{abstract}

Key words: gender violence; literature; equality; Emilia Pardo Bazán; education

1 Departamento de Lengua Española y Teoría de la literatura y Literatura Comparada

Universidad Complutense de Madrid

aliciafilol@gmail.com 
[fr] La violence sexiste dans les cours de littérature. Un projet pour augmenter la sensibilisation sur la violence sexiste dans les cours de littérature a travers les contes d'Emilia Pardo Bazán

Résumé. La violence sexiste est l'un des problèmes sociaux les plus importants de nos jours. Les lois à cet égard ont progressé au fur et à mesure pour garantir l'intégrité physique et psychologique des femmes victimes de ces abus. Cependant les meurtres et les abus se produisent encore et augmentent contre tout pronostic. Les dernières lois, autant celles exclusives de la violence sexiste comme celles qui réglementent les différents niveaux éducatifs, ont inclus l'éducation comme un objectif fondamental, puisqu'elle doit être le moteur qui construit des valeurs sur l'égalité des sexes et qui sensibilise sur la violence sexiste. Pour développer ce dur travail, on considère que les cours de littérature doivent être un outil fondamental pour le changement de la société. L'étude que l'on présente ci-dessous montre un projet pédagogique qui, à travers les contes d'Emilia Pardo Bazán, ne travaille que la critique littéraire mais aussi la critique sociale, mettant en relief la sensibilisation sur la violence sexiste.

Mots-clés: violence sexiste; littérature; égalité; Emilia Pardo Bazán; éducation.

Sumario: 1. Planteamiento del problema y justificación. 2. Fundamentación teórica. 2.1. La violencia de género: del siglo XIX a nuestros días. 2.2. La violencia de género en el aula de ESO, Bachillerato y Enseñanza para Adultos. 3. Estado de la cuestión: La violencia de género en el aula de literatura. 4. Objetivos. 5. Metodología. 6. Propuesta teórica. 7. Conclusiones. 8. Bibliografía. Anexos.

Cómo citar: Romero López, A. (2017). La violencia de género en el aula de literatura. Un proyecto por la sensibilización con la violencia de género en el aula de literatura a través de cuentos de Emilia Pardo Bazán. Didáctica. Lengua y literatura, 29, 2017, 235-258.

\section{Planteamiento del problema y justificación}

La violencia de género es uno de los problemas más acuciantes de la sociedad actual. En los seis primeros meses de 2016 ya han sido registradas 23 víctimas mortales a causa de este tipo de violencia, por lo que consideramos necesario que este tema sea trasladado al aula, ya que la educación, a todos los niveles, debe erigirse en estandarte de la igualdad y el respeto entre personas, ya sean de diferente sexo, raza o religión. Tanto el Gobierno Central como las diferentes Autonomías emprenden cada vez más campañas de sensibilización contra la violencia de género dirigidas a los diferentes ámbitos educativos, además de promulgar leyes específicas que asienten las bases de una sociedad más justa e igualitaria. Sin embargo, nos encontramos con que los casos de víctimas mortales en vez de disminuir, aumentan. Es por ello, por lo que consideramos que la sensibilización con la violencia de género ha de trasladarse directamente al aula, y hemos de trabajarla como parte de las diferentes materias y no como un elemento externo. El presente trabajo consiste en el diseño de una propuesta didáctica, orientada a alumnos de ESO, Bachillerato y Enseñanza para Adultos, en la que literatura y violencia de género queden ligadas.

Una precisión que consideramos necesaria hacer, ya que vamos a trabajar con la violencia de género, está relacionada con la propia palabra género, ya que muchas veces su uso resulta controvertido. La RAE no cuenta entre sus acepciones para esta palabra con una, que, sin embargo, es utilizada hoy en día “[...] la categoría de género 
es una definición de carácter histórico y social acerca de los roles, identidades y valores que son atribuidos a varones y mujeres e internalizados mediante los procesos de socialización" (Gamba, 2008). Para Judith Butler "la orientación sexual, la identidad sexual y la expresión de género, son el resultado de una construcción-producción social, histórica y cultural, y por lo tanto no existen papeles sexuales o roles de género, esencial o biológicamente inscritos en la naturaleza humana. En otras palabras, en términos de lo humano, la única naturaleza es la cultura" (Duque, 2010, 87). La identidad de género, para Butler, es un acto performativo que se construye cada día:

El género no está pasivamente inscrito sobre el cuerpo, y tampoco está determinado por la naturaleza, el lenguaje, lo simbólico o la apabullante historia del patriarcado. El género es lo que uno asume, invariablemente, bajo coacción, a diario e incesantemente, con ansiedad y placer, pero tomar erróneamente este acto continuo por un dato natural o lingüístico es renunciar al poder de ampliar el campo cultural corporal con performances subversivas de diversas clases (Butler, 1998, 314).

En este trabajo la palabra género se utilizará con este sentido, ya que consideramos que es el que mejor se adapta a la hora de hablar de violencia de género. Por otro lado, hemos de definir qué es la violencia de género, una de las definiciones legales más completas, y que será usada aquí como referente, es la que aparece en Ley 11/2007, de 27 de julio, gallega para la prevención y el tratamiento integral de la violencia de género:

Se trata de una violencia que afecta a las mujeres por el mero hecho de serlo. Constituye un atentado contra la integridad, la dignidad y la libertad de las mujeres, independientemente del ámbito en el que se produzca. Se entiende por violencia de género cualquier acto violento o agresión, basados en una situación de desigualdad en el marco de un sistema de relaciones de dominación de los hombres sobre las mujeres que tenga o pueda tener como consecuencia un daño físico, sexual o psicológico, incluidas las amenazas de tales actos y la coacción o privación arbitraria de la libertad, tanto si ocurren en el ámbito público como en la vida familiar o personal (I).

Consideramos que el trabajo que aquí estamos llevando a cabo es necesario y pertinente, no solo porque está tipificado en la Ley Orgánica 1/2004, de 28 de diciembre, de Medidas de Protección Integral contra la Violencia de Género, sino porque consideramos que la concienciación del alumnado respecto a la violencia de género es una obligación moral: "En la Educación Secundaria se incorpora la educación sobre la igualdad entre hombres y mujeres y contra la violencia de género como contenido curricular, incorporando en todos los Consejos Escolares un nuevo miembro que impulse medidas educativas a favor de la igualdad y contra la violencia sobre la mujer" (III).

El proyecto didáctico que aquí presentamos, amparado por el marco legal anteriormente citado, permitirá a los profesores de literatura concebir su asignatura como una herramienta válida para trabajar determinadas problemáticas sociales. Pensamos que el aula de literatura es y debe ser un espacio en el que a través de los textos literarios se debatan críticamente temas que conciernen a nuestro mundo actual. Para el desarrollo de este proyecto didáctico hemos considerado necesario realizar en un primer 
momento un acercamiento histórico a la evolución social y legal de la violencia de género. Por otro lado, también será de gran utilidad señalar algunas leyes que tipifiquen la concienciación contra la violencia de género en el ámbito educativo. Finalmente, se esquematiza el proyecto didáctico, pensado para $4^{\circ}$ de la $\mathrm{ESO}, 1^{\circ}$ de Bachillerato y $2^{\circ}$ ciclo de Enseñanzas para Adultos ${ }^{2}$, en el que a través de dos cuentos de Emilia Pardo Bazán, Las medias rojas y El encaje roto, no solo se trabajan las características del Realismo y el Naturalismo, sino que se dota de importancia a una autora, muchas veces olvidada o relegada a un segundo plano en los libros de texto. Además de todo ello, se trabajará la violencia de género a través de estos cuentos y de diferentes actividades relacionadas con la literatura y el contexto histórico-social.

\section{Fundamentación teórica}

Consideramos necesario basar nuestro proyecto didáctico en dos grandes pilares, por un lado en contextos histórico social de la mujer desde el siglo XIX hasta la actualidad, y por otro lado en las leyes, tanto educativas como específicas sobre violencia de género, que muestren que el proyecto que hemos diseñado es lícito y necesario.

\subsection{La violencia de género: del siglo XIX a nuestros días}

La evolución legal de las penas por violencia de género desde principios del XIX hasta principios del XX se sucedió como sigue:

El Código Penal de 1822 considera la relación de matrimonio como un atenuante cuando se trata de agresiones del marido a la esposa (arresto de 6 días) y como un agravante cuando se trata de agresión de la esposa al marido (prisión o trabajos forzosos de más de dos años). [...] El Código Penal de 1848 equiparaba los maltratos físicos del marido a la esposa con las provocaciones e injurias de la esposa al marido (arresto de uno a cuatro días o multa de uno a cuatro duros). El Código Penal de 1870 recogía en su texto la fórmula de la «venganza de la sangre», una facultad criminal concedida a los padres y maridos para matar a sus hijas y esposas, y a los hombres que yacían con ellas. Así, si una mujer era sorprendida con su amante y el marido la asesinaba, éste solo era penado con el destierro por un corto período de tiempo, pero, en el caso contrario, la mujer era castigada con pena de prisión perpetua. Si una mujer insultaba o desobedecía a su marido podía ser castigada con pena de cárcel (Zurita Bayona, 2013, 10).

A comienzos del siglo XX el hombre que mataba a su esposa adúltera podía excusarse en el concepto de honor medieval para minimizar el castigo ${ }^{3}$ :

En el Código Penal de 1902 se contemplaba simplemente la pena de destierro, y no de cárcel, para el marido que mataba a la mujer adúltera sorprendida con

Así mismo, creemos que con las debidas adaptaciones curriculares esta propuesta resulta extensible a otros niveles y contenidos educativos.

3 En este trabajo (Apartado 4.3.) se señalarán diversos artículos periodísticos de comienzos del siglo XX escritos por Emilia Pardo Bazán en los que condena esta injusticia legal. 
su amante (uxoricidio), pero nunca hubo precepto similar para la mujer que sorprendiera a su marido en análogas circunstancias. El uxoricidio era un delito que suponía un privilegio para el hombre en defensa de su honor [...] (Zurita Bayona, 2013, 10).

Durante la Segunda República se crearon una serie de políticas a favor de la igualdad entre mujeres y hombres a través de la Constitución de 1931 y de algunas leyes. Algunas de las medidas más importantes fueron: "[...] el matrimonio civil, basado en la igualdad entre los dos sexos, el divorcio, la despenalización del adulterio, la igualdad entre la descendencia dentro o fuera del matrimonio, la no discriminación en puestos oficiales y cargos públicos por razón de sexo, la protección de las mujeres en el trabajo y el sufragio universal" (Cases Sola, 2013).

Tras la Guerra Civil y con la llegada de la dictadura franquista la condición de la mujer empeoró severamente. Sírvanos como ejemplo la visión de la mujer transmitida por la asignatura de F.E.N. (Formación del Espíritu Nacional) o la Sección Femenina dirigida por Pilar Primo de Rivera, fundada en 1934 y no disuelta hasta 1977. A través de consignas reproducidas por todos los medios franquistas y amparadas por el dictador, la mencionada organización intentó (y en muchos casos consiguió) eliminar todas las conquistas obtenidas por las mujeres durante la II República. Estas mujeres se irguieron como las madres de la patria, y su discurso estuvo marcado por un ferviente catolicismo y la exaltación de la figura de la madre y de la esposa sumisa: "A través de toda la vida, la misión de la mujer es servir. Cuando Dios hizo el primer hombre, pensó: no es bueno que el hombre esté solo. Y formó a la mujer para su ayuda y compañía, y para que sirviera de madre. La primera idea de Dios fue el hombre. Pensó en la mujer después, como un complemento necesario, esto es, como algo útil"' (Otero, 2004, 24).

La mujer volvió a ser percibida como un ser inferior al hombre, tanto intelectual como biológicamente, y se le volvió a otorgar el papel de mera reproductora: "Las mujeres nunca descubren nada; les falta, desde luego, el talento creador, reservado por Dios para inteligencias varoniles; nosotras no podemos hacer nada más que interpretar, mejor o peor, lo que los hombres nos dan hecho" (Otero, 2004, 24). La subyugación a lo masculino queda claramente expresada en algunas de sus consignas: "Escúchale, déjale hablar primero. Recuerda que sus temas de conversación son más importantes que los tuyos. Nunca te quejes si llega tarde o si sale a cenar o a otros lugares de diversión sin ti. Intenta, en cambio, comprender su mundo de tensión y estrés, sus necesidades reales" (Sueiro Seoane, 2007, 106).

Si se entendía, por lo tanto, que la mujer era un ser inferior al hombre no ha de sorprendernos que la violencia de género estuviera a la orden del día y que incluso en el Código Penal de 1973 el "atenuante de 'estado pasional' fuera utilizado generosamente por parte de los jueces para reducir las penas a los hombres que agredían a sus mujeres, alegando que un arrebato pasional les había inducido a cometer la agresión" (Zurita Bayona, 2013, 11). Durante 40 años la mujer estuvo sometida a un discurso de inferioridad que caló socialmente, y es esta herida franquista la que hace que hoy en día no nos sorprendamos cuando observamos que la mujer sigue estando asociada al rol de madre y esposa.

Tras la muerte de Franco en el 1975 las evolución de las leyes contra la violencia de género no fue relevante, pues hasta 1983 el Código Penal español siguió considerando la relación conyugal como una atenuante en los malos tratos del hombre hacia 
la mujer (Zurita Bayona, 2013, 11). Habrá que esperar a 1995, con la creación de la Ley Orgánica 10/1995, de 23 de noviembre, del Código Penal, para que se tipifique como delito "[...] cualquier tipo de agresión, maltrato de obra, amenazas, coacciones o cualquier tipo de vejación, cometida por un hombre hacia su esposa, ex esposa o mujer que esté o haya estado ligada a él por una análoga relación de afectividad, aún sin convivencia, así como el quebrantamiento de la condena impuesta por este tipo de hechos" (Zurita Bayona, 2013, 12).

La legislación española no incorporó hasta 2015, en la Ley Orgánica 1/2015, de 30 de marzo, por la que se modifica la Ley Orgánica 10/1995, de 23 de noviembre, del Código Penal, el género como motivo de discriminación agravante (XXII). Aunque en los últimos años se ha avanzado mucho en materia de igualdad, aún contamos con una serie de concepciones sociales patriarcales que se expresan, por ejemplo, a través del humor, de determinados chistes o bromas misóginas, que aún hoy en día siguen siendo palmeados tanto por hombres como por mujeres. Este reparto injusto de roles acarrea que la mujer esté situada en un escalón social inferior, y que por ello sean necesarias estrategias y leyes que defiendan una igualdad real y que construyan una sociedad en la que la violencia de género no tenga cabida:

El Derecho penal parte aquí del reconocimiento de que la mujer, por su condición de tal y en virtud de la radical desigualdad en el reparto de roles sociales, se encuentra particularmente expuesta a sufrir ataques violentos a manos de su pareja masculina. Eso no significa negar la posibilidad de que el varón también pueda ser blanco de agresiones de su cónyuge o conviviente. La diferencia reside en que, en el caso de la mujer, a ese riesgo genérico de sufrir agresiones de la persona con la que se entabla una relación particularmente intensa -sea cual fuere su sexo-, se añade un peligro derivado de su propia condición femenina, un riesgo que tiene su origen en la radical injusticia en el reparto de roles sociales que coloca a las mujeres -como colectivo, como "género"- en una posición subordinada y dependiente del varón (Laurenzo, 2005, 17-18).

A las cifras de asesinadas, ya mencionadas, debemos añadir el número de mujeres que sufre, o ha sufrido, violencia física y psicológica, de las cuales no tenemos constancia más allá de los datos publicados en la Macroencuesta de Violencia contra la Mujer de 2015 en la que se recoge que el 12,5\% de las mujeres mayores de 16 años que viven en España ha sufrido violencia física o sexual de sus parejas o exparejas a lo largo de su vida. Por ello, consideramos necesario que la violencia de género sea un tema que se trate y se trabaje en todos los niveles educativos.

\subsection{La violencia de género en el aula de ESO, Bachillerato y Enseñanza para Adultos}

Creemos firmemente que la educación es una de las principales herramientas contra la violencia de género y así queda estipulado, por ejemplo, en el "Artículo 4, Principios y valores del sistema educativo", de la Ley Orgánica 1/2004, de 28 de diciembre, de Medidas de Protección Integral contra la Violencia de Género, que afirma: "1. El sistema educativo español incluirá entre sus fines la formación en el respeto de los derechos y libertades fundamentales y de la igualdad entre hombres y muje- 
res, así como en el ejercicio de la tolerancia y de la libertad dentro de los principios democráticos de convivencia".

Pero la violencia de género no solo aparece en leyes específicas sobre la misma, sino que también está presente en textos legales que versan sobre materia educativa. Tanto el "Artículo 11" del Real Decreto 1105/2014, de 26 de diciembre, por el que se establece el currículo básico de la Educación Secundaria Obligatoria y del Bachillerato como el "Artículo 3" del DECRETO 48/2015, de 14 de mayo, del Consejo de Gobierno, por el que se establece para la Comunidad de Madrid el currículo de la Educación Secundaria Obligatoria, establecen como uno de sus principales objetivos:

La Educación Secundaria Obligatoria contribuirá a desarrollar en los alumnos y las alumnas las capacidades que les permitan: [...] c) Valorar y respetar la diferencia de sexos y la igualdad de derechos y oportunidades entre ellos. Rechazar la discriminación de las personas por razón de sexo o por cualquier otra condición o circunstancia personal o social. Rechazar los estereotipos que supongan discriminación entre hombres y mujeres, así como cualquier manifestación de violencia contra la mujer.

Además, el "Artículo 9. Elementos transversales del currículo", del DECRETO $48 / 2015$ se afirma que se debe fomentar la prevención de la violencia de género en el aula: "2. La Comunidad de Madrid fomentará el desarrollo de los valores que potencien la igualdad efectiva entre hombres y mujeres y la prevención de la violencia de género, y de los valores inherentes al principio de igualdad de trato y no discriminación por cualquier condición o circunstancia personal o social".

Es curioso, sin embargo, que en la Orden EDU/1622/2009, de 10 de junio, por la que se regula la enseñanza básica para las personas adultas presencial y a distancia, en el ámbito de gestión del Ministerio de Educación, tan solo aparezca mencionada la violencia de género dentro de los objetivos del Nivel II de enseñanza pero no en el Nivel I. Además, esta es equiparada al ahorro de energía o la educación vial: "Manifestar interés, demostrando sentido crítico e iniciativa personal, ante campañas de sensibilización colectiva sobre aspectos relativos a la mejora de la convivencia y de un futuro sostenible como la educación vial, la violencia de género, ahorro de energía". Consideramos esta última afirmación un despropósito, ya que si todas las problemáticas señaladas no carecen de importancia, no pueden ser tratadas de la misma manera. Es llamativo que sea tan solo en la ley que regula la enseñanza para personas adultas donde no aparezcan referencias a la violencia de género, o al menos de forma tan explícita como en las anteriores leyes, aunque sí se busca fomentar los valores de igualdad entre hombres y mujeres y de la no discriminación. Pensamos que este hecho debería ser subsanado, ya que la legalidad vigente debe contemplar la lucha contra la violencia de género en todos los niveles educativos.

Actualmente existen muchos recursos, algunos de ellos dirigidos al ámbito educativo, que se dedican a la sensibilización con la violencia de género. Una web muy completa es la presentada por la Federación Española de Municipios y Provincias (FEMP) y el Ministerio de Sanidad, Servicios Sociales e Igualdad a través de la Delegación del Gobierno para la Violencia de Género ${ }^{4}$, que pone a disposición de

http://www.aulaviolenciadegeneroenlocal.es/consejosescolares/ 
los Consejos Escolares una guía para implicar al centro educativo en la eliminación de la violencia de género y de todas las formas de discriminación sobre las mujeres. Este recurso electrónico presenta como objetivo principal: "Dotar de herramientas a los Consejos Escolares para la erradicación del sexismo y de la violencia de género en el ámbito educativo".

Sin embargo, si bien hemos encontrado mucho material y recursos específicos para concienciar respecto a la violencia de género ${ }^{5}$, consideramos que estos están pensados para llevar a cabo en el Centro Educativo en general, o a través talleres "extraescolares". Es por ello, que el proyecto que aquí presentamos es novedoso, en tanto que lo que pretende es que la violencia de género sea trabajada transversalmente dentro del aula de literatura.

\section{Estado de la cuestión: la violencia de género en el aula de literatura}

Como ya se ha señalado en el apartado anterior, el Currículo promueve que en el aula se trabaje con los alumnos para fomentar la igualdad y para concienciar sobre la violencia de género. Sin embargo, llama la atención que si bien las leyes educativas tienen como uno de sus objetivos fundamentales el promover una igualdad real, no proporcionen medios ni instrucciones para alcanzar. Ejemplo de ello, ya aplicado al ámbito de la literatura es que en el Decreto 48/2015, en los contenidos de lengua y literatura castellana, para $3^{\circ}$ de la ESO, primer curso en el que se establece el estudio de la literatura por épocas y autores, tan solo encontramos a una escritora, Santa Teresa de Jesús. A partir de este punto, no aparecen citadas más literatas. Consideramos que esto contradice lo estipulado en el "Artículo 6. Fomento de la igualdad", de la Ley Orgánica 1/2004: "Con el fin de garantizar la efectiva igualdad entre hombres y mujeres, las Administraciones educativas velarán para que en todos los materiales educativos se eliminen los estereotipos sexistas o discriminatorios y para que fomenten el igual valor de hombres y mujeres".

Además, consideramos necesario señalar que los trabajos sobre el acercamiento de la sensibilización de la violencia de género al aula de literatura son prácticamente inexistentes. Un trabajo significativo es el artículo escrito por María Antonia Moreno Llaneza en la revista Tabanque, titulado "La literatura universal como recurso de aula para la prevención de la violencia contra las mujeres" (2010). En este caso trabaja con la asignatura de Literatura Universal, fomentando la presencia, olvidada, de la mujer en las diferentes literaturas.

Para reafirmarnos en nuestra propuesta queremos señalar una noticia aparecida en el periódico eldiario.es, en la que se muestra como un libro de $3^{\circ}$ de la ESO de Biología y Geología de la editorial Santillana contradice la ley al definir la violencia de género como sigue: "Malos tratos físicos o psicológicos que sufre una persona por parte de personas del sexo opuesto que tratan de ejercer sobre ella algún tipo de abuso o violencia" (Borraz, 2016). La violencia de género es la ejercida por el hombre sobre la mujer por el mero hecho de serlo. Las condiciones socio-históricas, reflejadas en apartados anteriores de este trabajo, dejan claramente expuesta la problemática de la mujer, que durante siglos ha sido entendida y tratada como un ser

En la bibliografía (Webs y Materiales en línea sobre la Violencia de Género) se encuentra un listado con las páginas web y recursos online más significativos a este respecto. 
inferior al hombre. Este ejemplo nos reafirma en la idea de que las aulas, independientemente de la materia que se imparta en ellas, tienen que ser un espacio perfecto para fomentar la igualdad y desterrar los roles de género, así como para trabajar la violencia de género.

\section{Objetivos}

Los objetivos principales del proyecto son:

- Reflexionar sobre el papel de la mujer en la literatura (como objeto y sujeto literario) a lo largo de los siglos y en la actualidad.

- Abordar la literatura en relación a la crítica social.

- Reflexionar críticamente sobre la violencia de género a través de la literatura.

- Concienciar sobre los diferentes tipos de violencias de género.

- Dar a conocer a Emilia Pardo Bazán, una de las autoras más importantes del panorama literario en lengua castellana.

- Contribuir al desarrollo de los escasos estudios que introducen la concienciación sobre la violencia de género en el aula de literatura.

- Fomentar el hábito de lectura entre los jóvenes, a través de textos que puedan servirles como espacio de reflexión sobre problemas actuales.

- Explorar y explotar la creatividad de los alumnos desde la escritura de cuentos.

- Desarrollar el diálogo y la tolerancia en el grupo.

\section{Metodología}

En lo que a la metodología utilizada comenzaremos por mencionar que la motivación de los alumnos es un elemento fundamental para el proceso de enseñanza, por lo que, a la hora de crear un clima favorable para el desarrollo satisfactorio del proyecto, buscaremos centrar su aprendizaje en potenciar sus propias capacidades, desarrollar su creatividad y acercar los temas tratados a su vida cotidiana.

Las clases estarán basadas y sustentadas en la igualdad entre alumnos y alumnas. Los comportamientos discriminatorios o misóginos serán cortados de raíz, creando un espacio libre de comportamientos machistas. El aula de literatura, así como la de las demás materias, debe ser concebida como un lugar en el que la libertad de expresión y el espíritu crítico sean las bases de la convivencia entre los alumnos. El lenguaje en el aula estará libre de prejuicios, será de carácter no sexista y, además, se alejará de todo tipo de estereotipos sociales y culturales.

La visibilización de la mujer será otro de los aspectos fundamentales a tener en cuenta a la hora de trabajar con los alumnos en el aula de literatura. Normalmente las escritoras quedan fuera del canon literario marcado en los libros de texto, por lo que debemos dar visibilidad a todas las escritoras que lucharon por una sociedad más justa e igualitaria. Al igual que damos voz a las autoras olvidadas, también debemos hacerlo metodológicamente, dando voz tanto a alumnas como a alumnos por igual. 
Por otro lado, el aula debe ser un foro de debate, en el que todas las alumnas y alumnos puedan intervenir y defender sus argumentos de forma activa. Solo con una metodología participativa, en la que el profesor ceda protagonismo a los alumnos, conseguiremos que estos formen parte activa de los debates del aula, fomentando así la autoestima de nuestros alumnos. Además, si proponemos temas atractivos para los estudiantes, conseguiremos que la motivación de los mismos aumente, haciendo del debate una de las partes más importantes del aula de literatura.

A todo ello debemos sumar que el enfoque metodológico es transversal, ya que se trabajarán con textos literarios, periodísticos e históricos. Además, se trabajará, siempre que nos sea posible, con el método inductivo. Pensamos que este método es el que mejor complementa la idea de un aula participativa y activa. Los alumnos deben ser los protagonistas de su propio aprendizaje, lo que además, en nuestra opinión, les ayuda a ser dueños de sus reflexiones, es decir, a desarrollar un pensamiento propio. Sin embargo, para que los conceptos queden claros y sean homogéneos, el profesor se servirá del método deductivo para clarificar las dudas que hayan surgido y organizar las ideas.

Para finalizar, se ha de señalar que también se trabajará con la investigación cuantitativa, pues se pasará una encuesta a los alumnos (Anexo I), al comienzo de la primera sesión y al finalizar la tercera, con el fin de analizar sus ideas previas y comprobar si estas varían después del análisis realizado en clase.

\section{Propuesta teórica}

En este apartado se especificará la propuesta teórica que aúna literatura y violencia de género. Las sesiones están pensadas para ser llevadas a cabo una vez finalizadas la unidad didáctica referente al Realismo literario.

Planificación de las sesiones:

Primera sesión (50 minutos)

- Cuestionario: antes de llevar a cabo las sesiones se pasará un cuestionario a los alumnos (Anexo I), dividido en tres apartados de contenido: literario, desigualdades sociales y violencia de género. (Tiempo estimado: 10 minutos)

- Introducción "La mujer en el siglo XIX": consideramos fundamental el estudio del contexto histórico para poder analizar en profundidad los textos literarios. En este caso se parte del supuesto de que los estudiantes ya han visto las características históricas del siglo XIX, por lo que nosotros tan solo daremos unas breves pinceladas sobre la situación de la mujer a finales del siglo XIX (ver punto 2.1. del presente trabajo). (Tiempo estimado: 10 minutos)

- Contrato de Maestras: para despertar el interés del alumnado y atraer su atención sobre las diferencias de género se trabajará con un documento histórico de 1923 (Anexo II): un contrato de maestras, en el cual se le pide a las futuras profesoras que cumplan con una serie de obligaciones tales como: "no pasearse por heladerías de la ciudad". La problemática derivada de este texto se cifra en que incluso hoy en día, aunque alguna de las obligaciones nos parezca descabellada, no nos alarmamos, porque entendemos que esas desigualdades sociales han existido siempre. Sin embargo, ¿qué pasaría si nos topáramos con un contrato para maestros del mismo estilo? La dinámica relativa a este 
apartado consiste en crear un contrato ficticio para maestros (Anexo III) siguiendo las pautas del real establecido para las mujeres. En primer lugar se les presenta a los alumnos el ficticio, para que reflexionen sobre lo que allí aparece, y posteriormente el real. Los alumnos tendrán que argumentar si los dos textos les parecen verídicos o no. Esta dinámica de grupo potenciará no solo el debate y la argumentación en el aula, sino que servirá al profesor como forma de toma de contacto con las ideas previas del alumnado. (Tiempo estimado: 15 minutos)

- Emilia Pardo Bazán: en este apartado se realizará una breve introducción a la figura de la autora gallega. Se hará hincapié en el hecho de que el padre de Emilia Pardo Bazán facilitó el acceso a los estudios de la misma, así como en su pertenencia a una familia noble y acomodada. Con ello, queremos trabajar el concepto de independencia económica o de "habitación propia" ya señalado en el cuestionario, pues consideramos necesario que los alumnos sean conscientes de las dificultades que aún en el XIX existían para que las mujeres accedieran a la educación y pudieran dedicarse a la escritura. Se tratará a Emilia Pardo Bazán como una de las grandes escritoras e intelectuales del siglo XIX, que tuvo contacto, incluso personal, con grandes escritores de la época como Galdós y Clarín, resaltando a su faceta de mujer liberada que abogó por los derechos de las mujeres. Sin embargo, también fue muy criticada en la época por algunos de sus colegas masculinos. La propia autora gallega afirma: "la mujer es tanto más apta para su providencial destino cuanto más ignorante y estacionaria, y la intensidad de educación, que constituye para el varón honra y gloria, para la hembra es deshonor y casi monstruosidad" (Pardo Bazán, 1999, 152). Emilia Pardo Bazán fue una gran defensora de la educación de la mujer, que en su época "no ha sido creada más que para el hombre; no tiene existencia propia ni individualidad fuera de su marido e hijos" (Pardo Bazán, 1999, 154).

- Para finalizar y para que se comprenda la difícil empresa de Pardo Bazán, a quien aquí utilizamos como símbolo de las demás escritoras de la época, se explicará a los alumnos que, si bien fue una de las más relevantes intelectuales de finales del XIX y principios del XX, se le denegó la entrada a la Real Academia Española tan solo por el hecho de ser mujer. En 1853 "los académicos llegan a un acuerdo mediante votación pública y cierran las puertas de la RAE a las mujeres" (Charques Gámez, 2003, 13). (Tiempo estimado: 15 minutos)

- Al finalizar la clase se repartirá una fotocopia con los cuentos Las medias rojas y El encaje roto y unos fragmentos de los Pazos de Ulloa (Anexo IV). Los alumnos deberán leer el cuento Las medias rojas antes de la siguiente clase.

Segunda sesión (50 minutos)

- Reflexión inicial: con el fin de asentar las reflexiones realizadas en la sesión anterior y para seguir debatiendo sobre la situación de las escritoras en el mundo literario se entregarán algunos textos, que serán leídos en alta. Estas reflexiones sobre los problemas y dificultades que han tenido y tienen las mujeres en el ámbito literario. La primera cita pertenece a María de Zayas:

Quién duda, lector mío, que te causará admiración que una mujer tenga despejo no solo para escribir un libro, sino para darle a estampa, que es el crisol donde se ave- 
rigua la pureza de los ingenios. [...] Quien duda, digo otra vez, que habrá muchos que atribuyan a locura esta virtuosa osadía de sacar a la luz mis borrones, siendo mujer, que en opinión de algunos necios es lo mismo que una cosa incapaz. [...] Porque si esta materia de que nos componemos los hombres y las mujeres, ya sea una trabazón de fuego y barro, o ya una masa de espíritus y terrones, no tiene más nobleza en ellos que en nosotras; si es una la misma sangre; los sentidos, las potencias y los órganos por donde obran sus efectos son unos mismos; la misma alma que ellos, porque las almas ni son hombres ni mujeres; ¿Qué razón hay para que ellos sean sabios y presuman que nosotras no podemos serlo? (Zayas, 2000, 159). ¿Por qué, vanos legisladores del mundo, atáis nuestras manos para las venganzas, imposibilitando nuestras fuerzas con vuestras falsas opiniones, pues nos negáis letras y armas? ¿El alma no es la misma que la de los hombres? ...; y así por tenernos sujetas desde que nacemos vais enflaqueciendo nuestras fuerzas con los temores de la honra, y el entendimiento con el recato de la vergüenza, dándonos por espadas ruecas, y por libros almohadilla (Zayas, 2000, 364).

Después de esta lectura se les preguntará por su opinión al respecto y se abrirá un turno de palabra para que comenten cuántas autoras han estudiado durante sus estudios de educación secundaria. Se parte de la idea de que conocen a Rosalía de Castro, ya que la Unidad Didáctica del Romanticismo es inmediatamente anterior a la que aquí estamos trabajando. Por ello, la cita que se leerá a continuación pertenece a la autora gallega:

Antes de escribir la primera página de mi libro, permítase a la mujer disculparse de lo que para muchos será un pecado inmenso e indigno de perdón, una falta de que es preciso que se sincere. Bien pudiera, en verdad, citar aquí algunos textos de hombres célebres que, como el profundo Malebranche y nuestro sabio y venerado Feijoo, sostuvieron que la mujer era apta para el estudio de las ciencias, de las artes y de la literatura. Posible me sería añadir que mujeres como madame Roland, cuyo genio fomentó y dirigió la Revolución francesa en sus días de gloria; madame Staël, tan gran política como filósofa y poeta; Rosa Bonheur, la pintora de paisajes sin rival hasta ahora; Jorge Sand, la novelista profunda, la que está llamada a compartir la gloria de Balzac y Walter Scott; Santa Teresa de Jesús, ese espíritu ardiente cuya mirada penetró en los más intrincados laberintos de la teología mística; Safo, Catalina de Rusia, Juana de Arco, María Teresa, y tantas otras, cuyos nombres la historia, no mucho más imparcial que los hombres, registra en sus páginas, protestaron eternamente contra la vulgar idea de que la mujer solo sirve para las labores domésticas y que aquella que, obedeciendo tal vez a una fuerza irresistible, se aparta de esa vida pacífica y se lanza a las revueltas ondas de los tumultos del mundo, es una mujer digna de la execración general. [...] Pasados aquellos tiempos en que se discutía formalmente si la mujer tenía alma y si podía pensar [...] se nos permite ya optar a la corona de la inmortalidad, y se nos hace el regalo de creer que podemos escribir algunos libros, porque hoy, nuevos Lázaros, hemos recogido estas migajas de libertad al pie de la mesa del rico, que se llama siglo XIX (Castro, 1986, 15-17).

Tras estas lecturas se les preguntará si piensan que en la actualidad la mujer está relegada a un segundo plano en el ámbito literario, aunque no existan tantas dificul- 
tades como hace siglos. Para fomentar el debate y así trabajar con los alumnos sobre cómo funciona el canon literario y el mercado editorial, se les hablará de la polémica creada por Chus Visor, uno de los editores de poesía más importantes e influyentes en España, quien en una entrevista para El Cultural afirmó:

Lo siento, pero creo que la poesía femenina en España no está a la altura de la otra, de la masculina, digamos, aunque tampoco es cosa de diferenciar. Desde luego, si vas a coger a las poetas desde el 98 para acá, es decir, todo el siglo XX, no ves ninguna gran poeta, ninguna, comparable a lo que suponen en la novela Ana María Matute o Martín Gaite. No hay una poeta importante ni en el 98, ni en el 27, ni en los 50, ni hoy. Hay muchas que están bien, como Elena Medel, pero no se la puede considerar, por una Medel hay cinco hombres equivalentes (Azancot, 2015).

Si una persona de su relevancia afirma públicamente que las mujeres escriben peor que los hombres, colocándolas así en un segundo plano del panorama literario, es obvio que en sus colecciones poéticas, o jurados en los que participe, su misoginia conseguirá que las mujeres no tengan significación literaria. Consideramos que estas reflexiones son necesarias dentro del aula de literatura para que los alumnos esclarezcan las dudas que les puedan surgir al no encontrar en sus libros de textos más que alguna referencia a determinadas escritoras. (Tiempo estimado: 20 minutos)

Lectura en alto del cuento Las medias rojas. Se trabajará el vocabulario con los alumnos. (Tiempo estimado: 10 minutos)

Análisis formal del cuento Las medias rojas: se trabajarán con los alumnos las características del texto naturalista. Se hará hincapié en las diferencias con el Realismo, sobre todo a través de la explicación de los conceptos de positivismo, determinismo y materialismo. También creemos que este cuento nos sirve como ejemplo para poner de relieve cómo tanto naturalistas como realistas utilizan muchas fórmulas comunes. El final del cuento, con la pérdida de toda esperanza por parte de Ildara, es un perfecto ejemplo para que los alumnos asienten sus conocimientos sobre la literatura naturalista. Serán los propios alumnos, con ayuda del profesor, los que reconozcan las características naturalistas del texto, aplicando así una metodología inductiva. Para que los alumnos comprueben esto por sí mismos se les hablará de la obra Los pazos de Ulloa y se les repartirán unos fragmentos de la misma (Anexo IV). Estos textos serán leídos en alto y se preguntará a los alumnos si consideran que los textos son naturalistas o realistas, para lo que deberán dar argumentos basados en citas del propio texto. En la pizarra se realizará un esquema con las características más importantes del Naturalismo. (Tiempo estimado: 20 minutos)

Los alumnos habrán de leer para la próxima sesión el cuento El encaje roto de Emilia Pardo Bazán.

\section{Tercera sesión (50 minutos)}

- Análisis crítico del cuento Las medias rojas: en esta segunda parte se reflexionará con los alumnos sobre el tema de la violencia de género a través del cuento Las medias rojas de Emilia Pardo Bazán. El cuento narra la historia de Ildara, una aldeana que vive con su tío y anhela emigrar a las Américas. La protagonista nos es presentada como una chica joven y coqueta "peinada "a la moda de las señoritas"". Mientras su tío pica un cigarro, ella prepara la 
lumbre y comienza a hacer la comida. A continuación se nos muestra cómo el tío observa que Ildara lleva unas medias rojas, lo que constituirá el desencadenante de la pelea que se va a suceder, en la cual la joven recibe una paliza que la deja tuerta:

Y con el cerrado puño hirió primero la cabeza, luego, el rostro, apartando las medrosas manecitas, de forma no alterada aún por el trabajo, con que se escudaba Ildara, trémula. El cachete más violento cayó sobre un ojo, y la rapaza vio como un cielo estrellado, miles de puntos brillantes envueltos en una radiación de intensos coloridos sobre un negro terciopeloso. Luego, el labrador aporreó la nariz, los carrillos. Fue un instante de furor, en que sin escrúpulo la hubiese matado, antes que verla marchar, dejándole a él solo, viudo, casi imposibilitado de cultivar la tierra que llevaba en arriendo, que fecundó con sudores tantos años, a la cual profesaba un cariño maquinal, absurdo. Cesó al fin de pegar; Ildara, aturdida de espanto, ya no chillaba siquiera. Salió fuera, silenciosa, y en el regato próximo se lavó la sangre. Un diente bonito, juvenil, le quedó en la mano. Del ojo lastimado, no veía (Pardo Bazán, 2007).

Esta paliza no solo la destruye física, sino también psicológicamente, ya que solo las muchachas guapas podían emigrar, por lo que su tío la condena de por vida a recluirse en la aldea. Se reflexionará con los alumnos sobre el porqué de la paliza: por un lado, el egoísmo del tío, quien intuye que su sobrina se va a marchar y le va a dejar solo; y por otra parte, la introducción de un elemento novedoso, las medias, como signo de la feminidad y coquetería de la sobrina. En este punto se mencionará a los alumnos las leyes sobre la violencia de género existentes en la época (véase punto 2.1. de este trabajo) y además la explicación se complementará, para suscitar el debate, con la proyección de un cartel actual contra la violencia de género (Anexo V) que reza: "Nadie me preguntó cómo vestía mi agresor". Con esta provocación queremos conseguir que los alumnos reflexionen cómo aún hoy en día las mujeres son objeto de insultos o de culpabilización por el simple hecho de la ropa que visten.

Tras estas reflexiones se añadirán las que los alumnos hayan sacado tras su lectura del cuento El encaje roto, cuento en el que una mujer abandona a su novio antes de llegar al altar porque descubre su verdadera personalidad e intuye cómo será su futuro junto a él: "[...] la cara de Bernardo, contraída y desfigurada por el enojo más vivo; sus pupilas chispeantes, su boca entreabierta ya para proferir la reconvención y la injuria... No llegó a tanto porque se encontró rodeado de gente; pero en aquel instante fugaz se alzó un telón y detrás apareció desnuda un alma" (Pardo Bazán, 2001).

En este cuento la violencia de género no se muestra de forma explícita, sino que a través por la reacción del hombre se deja intuir cómo va a ser el matrimonio: desigual, violento y de opresión y subyugación de la mujer. (Tiempo estimado: 25 minutos)

- La violencia de género en la prensa: Emilia Pardo Bazán, además de ser una de las escritoras de cuentos más prolíficas del siglo XIX, creó varias revistas y fue asidua escritora en prensa. Se entregarán a los alumnos dos textos (Anexo VI), crónicas de sociedad que versan sobre la violencia de género, extraídos de la revista La ilustración artística, creada por Emilia Pardo Bazán. Un texto es de 1901 y el otro de 1915, ambos escritos por la autora gallega. Las dos 
noticias versan sobre el asesinato de mujeres y la impunidad de los asesinos. La autora afirma: "Con razón decía un célebre jurisconsulto que la vida no está protegida; pero debió añadir 'en especial, la de la mujer'" (Pardo Bazán, 1915, 302). Estos textos se complementarán con referencias a las leyes sobre violencia de género, tanto del XIX como actuales (véase punto 2. de este trabajo). Con esta actividad se quiere hacer hincapié en la evolución positiva respecto a las leyes contra la violencia de género, pero también hacer reflexionar a los alumnos sobre cómo la frase con la que Pardo Bazán su texto de 1901, "los crímenes [contra las mujeres] continúan a la orden del día" (410), sigue pudiendo ser un titular de los periódicos actuales. (Tiempo estimado: 20 minutos)

- Mini-taller literario: para finalizar estas sesiones se pedirá a los alumnos que escriban un cuento ficcionalizando una noticia. Emilia Pardo Bazán escogió una de las problemáticas más importantes de su época, la violencia de género, y la convirtió en cuento y los alumnos deberán hacer lo mismo. Además se les pedirá que el cuento sea naturalista, es decir, que utilicen algunas de las características de este movimiento literario vistas en clase y las apliquen en sus textos. Con ello lo que se busca fomentar es la escritura y la reflexión crítica y que a la vez asienten los conocimientos teóricos sobre el Naturalismo. Creemos que la ficcionalización de una noticia que es altamente positivo, ya que de ese modo los alumnos asociarán el texto escrito a un elemento de su realidad, motivándolos no solo a la hora de escribir, sino también de enfrentarse a la literatura. Cuando los cuentos sean entregados a la profesora, esta los irá corrigiendo y devolviéndoselos para que los revisen hasta llegar a un texto definitivo. (Tiempo estimado: 5 minutos)

- Cuestionario: se volverá a pasar a los alumnos el cuestionario para que lo lean detenidamente y lo contesten. Se recogerá en la siguiente sesión.

\section{Conclusiones}

A modo de conclusión general se debe señalar que este estudio es en gran medida novedoso, ya que la violencia de género se trabaja dentro de los centros educativos, pero fuera de las aulas. Consideramos que para que la concienciación contra la violencia de género o contra otras problemáticas sociales sea realmente efectiva necesita de un trabajo continuo en el que tanto profesores y directiva como alumnos estén implicados. Partiendo de esta hipótesis se construyó una propuesta didáctica que en tan solo tres sesiones configura un modelo de enseñanza de la literatura en el que no se trabaja el texto por el texto. En este caso, la literatura nos ha servido como herramienta para que los alumnos reflexionen sobre su presente y sobre la violencia de género a través de textos de hace más de un siglo. Con ello, se consigue que el alumnado esté altamente motivado, pues ven en la literatura clásica reflejos de su cotidianeidad.

El aula no es solo un lugar de aprendizaje, sino un espacio en el que compartir experiencias e involucrarnos de forma más humana. No podemos trabajar en aulas asépticas que obvien las problemáticas personales de los alumnos, sino que debemos crear un clima en el que todo el mundo se sienta libre y en el que el aprendizaje sea 
un elemento más con el que poder desarrollarnos como personas. Creemos que el aula de literatura es un espacio perfecto para acercar a los alumnos a determinadas problemáticas sociales a través de textos literarios, alejándonos así del estudio de la forma y el contenido del texto de forma neutral. La literatura como herramienta social puede constituir un arma con la que conseguir que los alumnos alcancen un pensamiento crítico propio. Este último concepto es fundamental, ya que solo a través de la conciencia crítica podremos realizar un análisis detallado de la realidad y así poder observar todos estos comportamientos como una forma de representación de la sociedad patriarcal, distanciarnos de ellos y seguir trabajando por una igualdad real.

La lucha de las mujeres para acceder a los derechos fundamentales no debe quedar en el olvido y nosotros, como profesores, debemos visibilizarla en nuestras aulas. La literatura es una herramienta de la que podemos servirnos para alcanzar este propósito, que, como se ha demostrado aquí, es posible y necesario.

\section{Bibliografía}

Azancot, Nuria (2015): “Entrevista a Chus Visor”, El Cultural, 26 de junio de 2015. http:// www.elcultural.com/revista/letras/Chus-Visor-Dicen-que-los-novelistas-son-vanidosos-pero-hay-cada-poeta/36667?intcmp=HEMSUPL [consulta: 3 septiembre 2017].

Borraz, Marta (2016): "Un libro de la ESO contradice la ley y enseña que violencia de género es también de mujer contra hombre", El Diario, 21 de abril de 2016. http://www. eldiario.es/sociedad/secundaria-engloba-violencia-ejercida-hombres_0_507799985.html [consulta: 3 septiembre 2017].

Butler, Judith (1998): “Actos performativos y constitución del género: un ensayo sobre fenomenología y teoría feminista", Debate Feminista, 18, 296-314.

Capel Martínez, Rosa Ma (2006): "La mujer española en el XIX: coordenadas históricas", en Con voz propia: la mujer en la literatura española de los siglos XIX y XX, María Pilar Celma Valero, Carmen Morán Rodríguez (eds.), Junta de Castilla y León, Instituto Castellano y Leonés de la Lengua, 17-28.

Cases Sola, Adriana (2013): "La violencia de género en la Segunda República", Hispania Nova: Revista de Historia Contemporánea, 11.

Castro, Rosalía de (1986): La hija del mar. Madrid, Akal.

Charques Gámez, Rocío (2003): Los artículos feministas en el "Nuevo teatro crítico" de Emilia Pardo Bazán. Alicante, Centro de Estudios sobre la Mujer.

Díaz Lage, Santiago y José Manuel González Herra (ed.) (2016): Leyendo a Emilia Pardo Bazán en el aula, Santiago de Compostela, Andavira Editora.

Duque, Carlos (2010): "Judith Butler y la teoría de la performatividad de género", Revista de Educación y Pensamiento, 17, 85-95.

Gamba, Susana (2008): “¿Qué es la perspectiva de género y los estudios de género?”, Mujeres en Red.www.mujeresenred.net/spip.php?article1395 [consulta: 3 septiembre 2017].

Herrera, Coral (2013): La construcción Sociocultural del Amor Romántico. Madrid, Fundamentos.

Laurenzo Copello, Patricia (2005): “La violencia de género en la Ley Integral. Valoración político-criminal", Revista Electrónica de Ciencia Penal y Criminología, 7, 1-23. http:// criminet.ugr.es/recpc/07/recpc07-08.pdf [consulta: 3 septiembre 2017]. 
Núñez Pérez, María Gloria (1998): "Políticas de igualdad entre varones y mujeres en la segunda república española”, Espacio, tiempo y forma. Serie V, Historia contemporánea, $11,393-446$.

Moreno Llaneza, María Antonia (2010): "La literatura universal como recurso de aula para la prevención de la violencia contra las mujeres", Tabanque, 23, 83-98.

Otero, Luis (2004): La Sección femenina, Madrid, Edaf.

Pardo Bazán, Emilia (1901): “La vida contemporánea”, La ilustración artística. 24 de junio de 1901, n 1017, 410.

Pardo Bazán, Emilia (1915): “La vida contemporánea”, en La ilustración artística. 3 de mayo de 1915, $n^{\circ} 1740,302$.

Pardo Bazán, Emilia (1999): La mujer española y otros escritos, Madrid, Cátedra.

Pardo Bazán, Emilia (2000): La madre naturaleza, Alicante, Biblioteca Virtual Miguel de Cervantes

Pardo Bazán, Emilia (2001): El encaje roto, Alicante, Biblioteca Virtual Miguel de Cervantes.

Pardo Bazán, Emilia (2007): Las medias rojas, Alicante, Biblioteca Virtual Miguel de Cervantes.

Ruiz-Ocaña, Eduardo (2004): "Emilia Pardo Bazán y los asesinatos de mujeres”, Revista Didáctica (Lengua y Literatura), 16, 177-188.

San Miguel Lobo, Cristobal (2015): Ámbito comunicación [II] Lengua castellana y literatura, Madrid, Editex.

Sueiro Seoane, Susana (2007): Posguerra: publicidad y propaganda (1939-1959), Madrid, Ministerio de Cultura, 2007

Tasende-Grabowski, Mercedes (1991): “Otra vez a vueltas con el naturalismo...”, Hispania, 74 (1), 26-35.

Vargas, Ángela (2009): “Métodos de Enseñanza”, Innovación y experiencias educativas, 15, 1-9. http://www.csi-csif.es/andalucia/modules/mod_ense/revista/pdf/Numero_15/ANGELA_VARGAS_2.pdf [consulta: 3 septiembre 2017].

Zayas y Sotomayor, María de (2000): Novelas amorosas y ejemplares, Madrid, Cátedra.

Zurita Bayona, Jorge (2013): "La lucha contra la violencia de género", Seguridad y Ciudadanía: Revista del Ministerio del Interior, 9, 63-127.

\section{Textos legales}

Ley Orgánica 10/1995, de 23 de noviembre, del Código Penal. Publicado en BOE, núm. 281 de 24 de noviembre de 1995.

Ley Orgánica 1/2004, de 28 de diciembre, de Medidas de Protección Integral contra la Violencia de Género. Publicado en BOE, núm. 313 de 29 de Diciembre de 2004

Ley 11/2007, de 27 de julio, gallega para la prevención y el tratamiento integral de la violencia de género. Publicada en DOG, núm. 152 de 7 de agosto de 2007.

Orden EDU/1622/2009, de 10 de junio, por la que se regula la enseñanza básica para las personas adultas presencial y a distancia, en el ámbito de gestión del Ministerio de Educación. Publicado en BOE, núm. 147 de 18 de junio de 2009.

Real Decreto 1105/2014, de 26 de diciembre, por el que se establece el currículo básico de la Educación Secundaria Obligatoria y del Bachillerato. Publicado en BOE núm. 3 de 3 de enero de 2015

Ley Orgánica 1/2015, de 30 de marzo, por la que se modifica la Ley Orgánica 10/1995, de 23 de noviembre, del Código Penal. Publicado en BOE, núm. 77 de 31 de marzo de 2015 
Decreto 48/2015, de 14 de mayo, del Consejo de Gobierno, por el que se establece para la Comunidad de Madrid el currículo de la Educación Secundaria Obligatoria. Publicado en BOCM, núm. 118 de 20 de mayo de 2015.

\section{Documentos oficiales sobre Violencia de Género}

Consejo de Europa (2011): Convenio del Consejo de Europa sobre prevención y lucha contra la violencia contra las mujeres y la violencia doméstica. http://www.msssi.gob.es/ssi/igualdadOportunidades/internacional/consejoeu/CAHVIO.pdf [consulta: 3 septiembre 2017].

ONU (1993): Declaración sobre la eliminación de la violencia contra la mujer. http://www. servindi.org/pdf/DecEliminacionViolenciaMujer.pdf [consulta: 3 septiembre 2017].

ONU (2013): Elementos esenciales de planificación para la eliminación contra la violencia de mujeres y niñas. http://www.endvawnow.org/uploads/modules/pdf/1372349315.pdf [consulta: 3 septiembre 2017].

OMS (2013): Violencia contra la mujer. http://www.who.int/mediacentre/factsheets/fs239/ es/ [consulta: 3 septiembre 2017].

VV.AA. (2015): "Macroencuesta de violencia contra la mujer". Ministerio de Sanidad, Servicios Sociales e Igualdad. http:/www.violenciagenero.msssi.gob.es/violenciaEnCifras/ macroencuesta2015/home.htm [consulta: 3 septiembre 2017].

\section{Webs y Materiales en línea sobre la Violencia de Género}

Aula Violencia de Género. http://www.aulaviolenciadegeneroenlocal.es/consejosescolares/ [consulta: 3 septiembre 2017].

Cortijo Calzada, María (2009): Educar para Prevenir. http://www.ayto-fuenlabrada.es/recursos/doc/SC/Mujer_juventud_infancia/Mujer/13252_2052052011101818.pdf [consulta: 3 septiembre 2017].

Gorrotxategi Larrea, Maite e Isabel Ma de Haro Oriola (1999): Materiales Didácticos para la Prevención de la Violencia de Género. Unidad Didáctica para Educación Secundaria http://www.aulaviolenciadegeneroenlocal.es/consejosescolares/archivos/Unidad_didactica_educacion_secundaria.pdf [consulta: 3 septiembre 2017].

Ruiz Pérez, Isabel (2003): Violencia contra la mujer y salud. Escuela Andaluza de Salud Pública. http://www.msssi.gob.es/organizacion/sns/planCalidadSNS/pdf/equidad/04modulo_03.pdf [consulta: 3 septiembre 2017].

VV.AA. (2004a): Estudio de investigación sobre el sexismo interiorizado presente en el sistema de creencias de la juventud adolescente de ambos sexos y su implicación en la prevención de la violencia de género en el contexto de pareja. http://www.fundacionmujeres. es/img/Document/14941/documento.pdf [consulta: 3 septiembre 2017].

VV.AA. (2004b): Juguemos... Guía de actividades para la coeducación y la no violencia de género. http://www.scout.es/uploads/genero/Juguemos.pdf [consulta: 3 septiembre 2017].

VV.AA. (2004c): Hacer los derechos realidad: Talleres de sensibilización sobre cuestiones de género y la educación en derechos humanos. http://www.educarenigualdad.org/ media/pdf/uploaded/material/353_hacer-los-derechos-realidadfinal-pdf.pdf [consulta: 3 septiembre 2017].

VV.AA. (2013): Unidad Didáctica "Prevención de la Violencia de Género en Jóvenes y Adolescentes". http://www.educarenigualdad.org/media/pdf/uploaded/material/306_u-d-violencia-de-gxnero-secundaria-pdf.pdf [consulta: 3 septiembre 2017]. 


\section{Anexo I}

\begin{tabular}{|c|c|c|}
\hline Hombre $\square$ & & \\
\hline Preguntas & SÍ & NO \\
\hline $\begin{array}{l}\text { ¿Crees que en la literatura se pueden reflejar determinados comportamientos } \\
\text { sociales? }\end{array}$ & & \\
\hline $\begin{array}{l}\text { ¿La literatura (independientemente de la época en la que se haya escrito) nos } \\
\text { puede ayudar a reflexionar sobre el mundo actual en el que vivimos? }\end{array}$ & & \\
\hline $\begin{array}{l}\text { ¿Crees que la literatura puede ser una herramienta para reflexionar sobre las } \\
\text { desigualdades sociales y mejorar la realidad? }\end{array}$ & & \\
\hline ¿Escriben mejor los hombres que las mujeres? & & \\
\hline $\begin{array}{l}\text { ¿Es por esta razón por la que el canon literario recoge más obras de hombres } \\
\text { que de mujeres? }\end{array}$ & & \\
\hline $\begin{array}{l}\text { ¿Crees que las mujeres necesitan una "habitación propia" para poder desa- } \\
\text { rrollar su profesión? }\end{array}$ & & \\
\hline ¿Y los hombres? & & \\
\hline $\begin{array}{l}\text { ¿Existe aún hoy en día discriminación hacia las mujeres en el ámbito litera- } \\
\text { rio? }\end{array}$ & & \\
\hline ¿Crees que existen estereotipos sociales sobre la mujer? & & \\
\hline ¿Y sobre el hombre? & & \\
\hline ¿Crees que existen desigualdades de género en la sociedad? & & \\
\hline ¿Consideras que el lenguaje refleja desigualdades de género? & & \\
\hline ¿Hay sexismo en la publicidad? & & \\
\hline $\begin{array}{l}\text { ¿Pueden las mujeres y la sociedad ser más activas para exponer públicamente } \\
\text { los problemas que afectan a las mujeres? }\end{array}$ & & \\
\hline ¿Están los hombres y mujeres educados en igualdad? & & \\
\hline $\begin{array}{l}\text { ¿Consideras que actualmente son necesarias más medidas para acabar con la } \\
\text { discriminación femenina? }\end{array}$ & & \\
\hline ¿La violencia solamente es de tipo físico? & & \\
\hline $\begin{array}{l}\text { ¿Consideras que humillar verbalmente a alguien, por ejemplo, por no cum- } \\
\text { plir los estereotipos de belleza, es una forma de violencia? }\end{array}$ & & \\
\hline $\begin{array}{l}\text { El problema del maltrato a las mujeres es un asunto privado donde es mejor } \\
\text { no entrometerse. }\end{array}$ & & \\
\hline
\end{tabular}




\section{Anexo II}

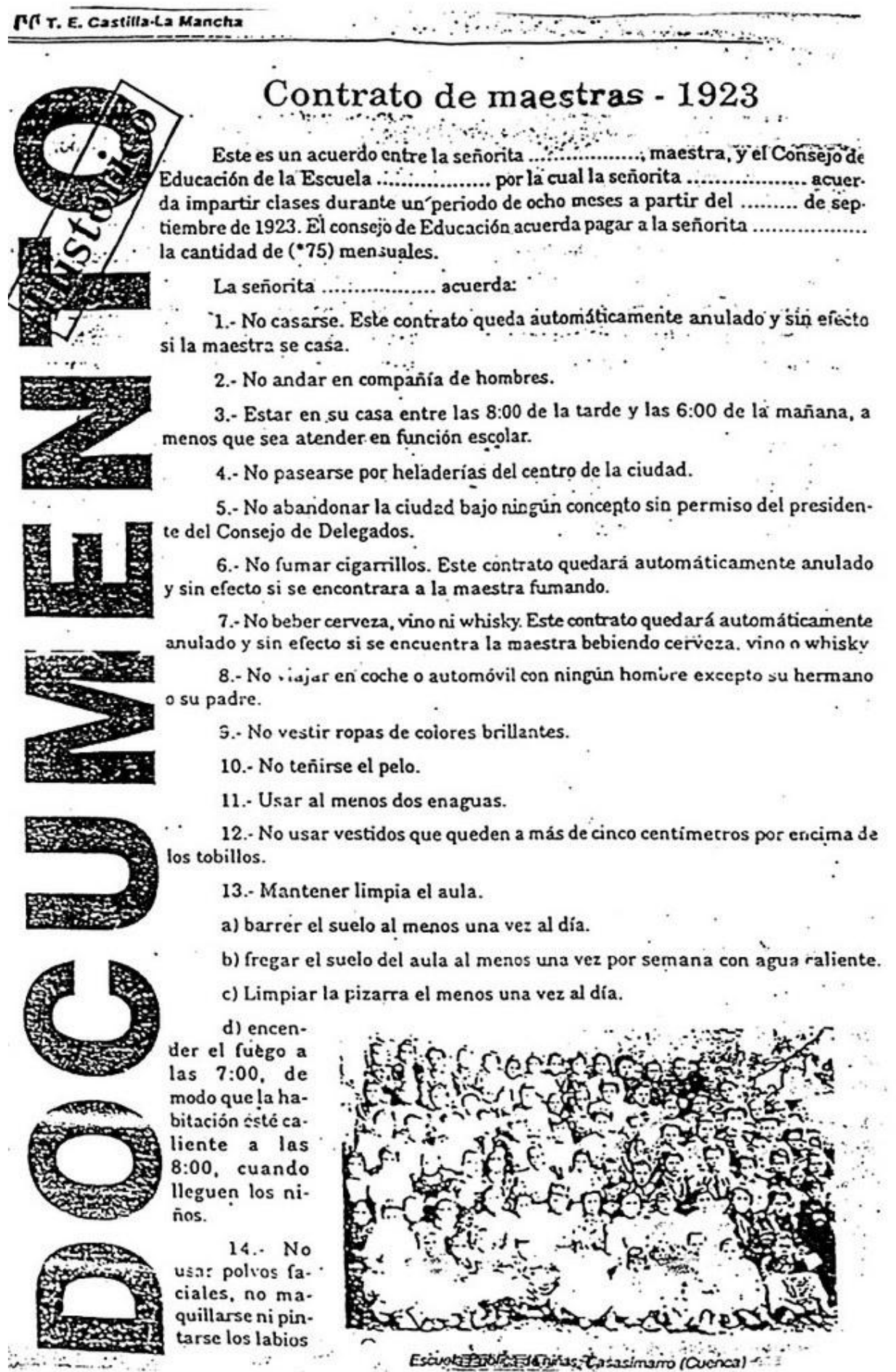


Anexo III

FT T. E. Castilla-La Mancha
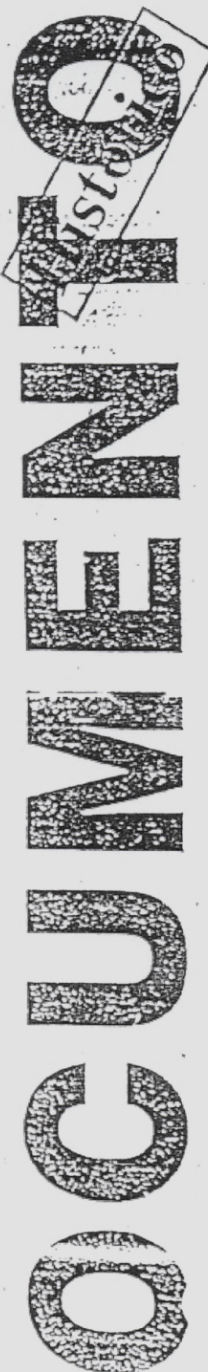

सका

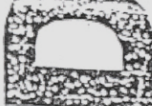
lar.

Consejo de Educación

\section{Sección Masculina}

Este es un acuerdo entre el señorito

maestro, y el Consejo de Educación de la Escuela

Por el cual el señorito

acuerda impartir clases duran-

te un periodo de ocho meses a partir del

de septiembre de 1923

El señorito

acuerda:

1. No tener relaciones sexuales con mujeres, ni dentro del matrimonio, ni fuera del mismo.

2. No andar en compañía de mujeres, exceptuando su hermana, mujer y madre.

3. Estar en su casa entre las 8:00 de la tarde y las 6:00 de la mañana, a menos que sea para atender función escolar. Durante estas horas deberá preparar la cena y tenerla lista para la hora en la que su mujer llegue a casa.

4. Deberá comportarse de forma dulce e interesante, escuchando y obedeciendo las directrices ta

nto de la directora como de las mujeres del Consejo Esco-

5. Queda estrictamente prohibido el consumo de dulces y otros alimentos calóricos

6. No beberá ningún tipo de bebida alcohólica, quedando reservado para el consumo del hombre todo tipo de tés y batidos naturales.

7. No fumar cigarrillos, ni puros; deberá mantener una correcta higiene bucal.

8. No podrá salir de casa ni viajar sin autorización expresa de su madre, mujer o directora del centro.

9. No vestir ropas que marquen su figura y provoquen a las mujeres del centro educativo.

10. Vestir al menos dos pares de calzoncillos.

11. No utilizar colonias.

12. Se ha de mantener un aspecto limpio, sano y agradable. ¡Ponte guapo, sin provocar!

13. Mantener limpia el aula: barrer y fregar los suelos, limpiar los baños, etc.

14. Todas las mañanas al Ilegar a la escuela habrá de preparar y servir el café a las maestras. 


\section{Anexo IV \\ Los pazos de Ulloa}

Como si también los perros comprendiesen su derecho a ser atendidos antes que nadie, acudieron desde el rincón más oscuro, y olvidando el cansancio, exhalaban famélicos bostezos, meneando la cola y levantando el partido hocico. Julián creyó al pronto que se había aumentado el número de canes, tres antes y cuatro ahora; pero al entrar el grupo canino en el círculo de viva luz que proyectaba el fuego, advirtió que lo que tomaba por otro perro no era sino un rapazuelo de tres a cuatro años, cuyo vestido, compuesto de chaquetón acastañado y calzones de blanca estopa, podía desde lejos equivocarse con la piel bicolor de los perdigueros, en quienes parecía vivir el chiquillo en la mejor inteligencia y más estrecha fraternidad. (II)

Hacía tiempo que el marqués no veía de cerca a Sabel. Más que mirarla, se puede decir que la examinó despacio durante algunos minutos. Reparó que la moza no llevaba pendientes y que tenía una oreja rota; entonces recordó habérsela partido él mismo, al aplastar con la culata de su escopeta el zarcillo de filigrana, en un arrebato de brutales celos. La herida se había curado, pero la oreja tenía ahora dos lóbulos en vez de uno. (XVII) 


\section{Anexo V}

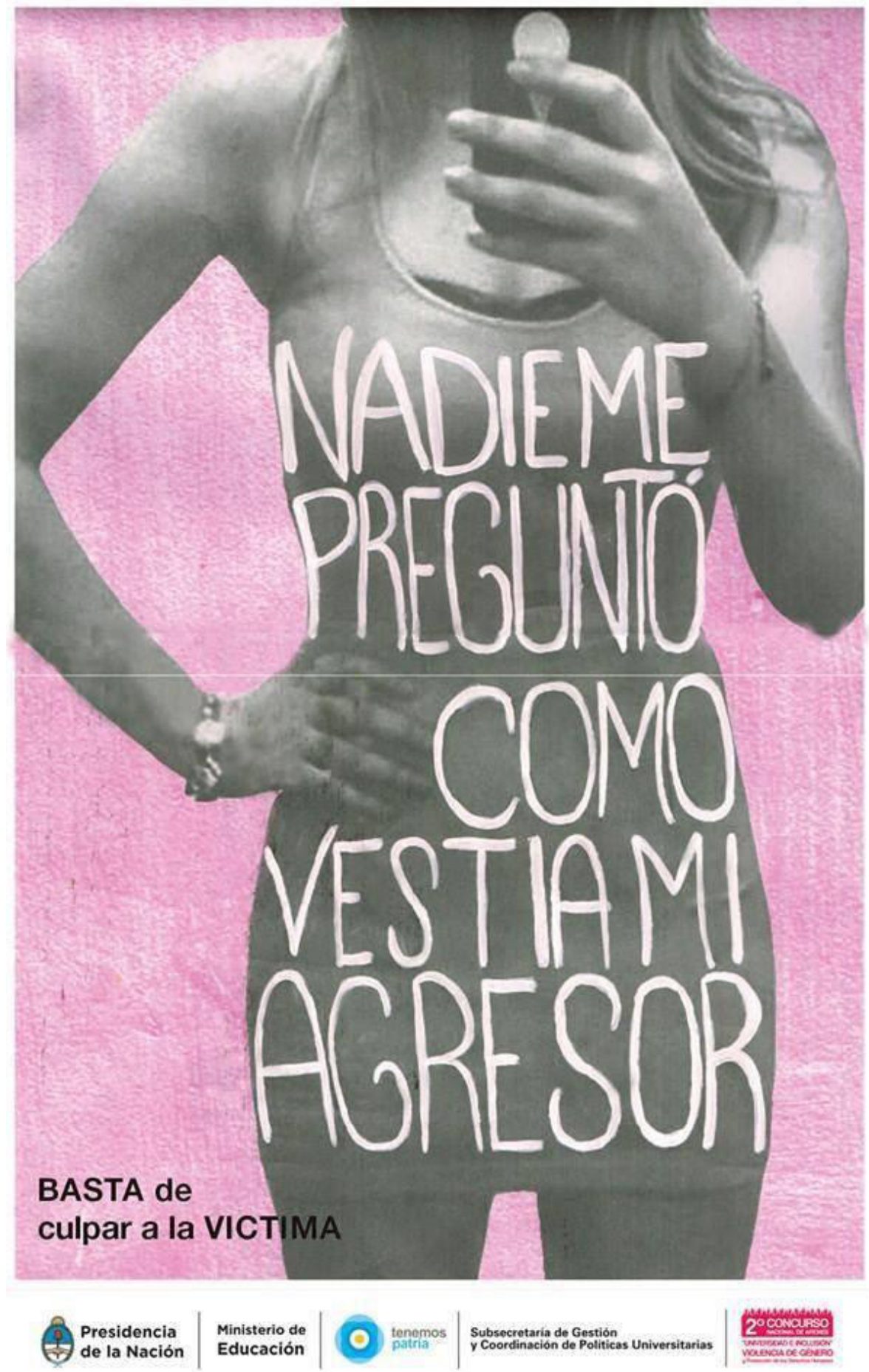




\section{Anexo VI}

A

Siguen a la orden del dia los asesinatos de muje. res. En esta semana hemos tenido nuestro corres. pondiente marido calderoniano. Mató a su cónyuge, con certeros tiros; pero, llegado el momento de ehacerse justicia», le falló... Pícara casualidad - que se da muy frecuentemente - .

$\mathrm{V}$ después, el toque teatral: el beso al cadáver, en la frente, con gran efusión...

Hacen bien estos médicos de su honra (la cual, la mayor parte de las veces, no ha sufrido deterioro, y ésta me parece una de ellas) en realizar todas las alharacas del sentimiento. Son la probable abso. lución del jurado, $y$ hasta los aplausos a la salida, y los apretones de manos, y el convite de los camaradas y los amigos...

$\mathrm{Y}$ cuatro huérfanos, $\mathrm{y}$ un hogar deshecho en un arrebato, $y$ un ser humano sacrificado sin miseri. cordia...

Con razón decia un célebre jurisconsulto que la vida no está protegida; pero debió añadir «en especial, la de la mujers. Todo español cree tener sobre la mujer derecho de vida o muerte. Lo mismo da que se trate de su novia, de su amante, de su esposa. Los celos disculpan los más atroces atentados, las venganzas más cruentas; y los que se escandalizan de las barbaridades de la guerra (que al fin tienen un carácter colectivo y de interés general) disculpan esas atrocidades individuales, como si fuese licito nunca tomarse la justicia por la mano.
Los crimenes continúan á la orden del día. Críme. nes pasionales, crímenes acompañados de robo: poca variedad, poca amenidad en este aspecto de la crónica. Cuando leo en un periódico «Horrible crimen, de antemano podría relatar lo que sigue. La variedad más frecuente es esta. Un obrero - hojalatero, zapatero, vidriero, ya se recordará la enumeración de $L a$ verbena de la Paloma - tiene relaciones con una mu chacha đque siempre fué honrá.» La muchacha, 6 porque su amartelado galán le pega, ó porque acostumbra estar beodo, 6 porque tiene sus queridas, 6 por cualquier otra fruslería del mismo jaez, determina romper y no acordarse más del santo del nombre de aquel individuo. Él no está conforme: desea continuar. Ella le significa su resolución: ćl se lamenta, se mesa los cabellos, profiere imprecaciones sordas y reniega de su indecente suerte. Ella, firme que firme.

Pasan dos meses 6 tres. La muchacha, aburrida de coser $\delta$ de fregar, decide asistir á un baile ó darse una vuelta por la plazuela. El ex novio la sigue allí, y apenas le echa la vista encima, la apremia para reanudar. Niégase la chica por última vez; el galán saca un revólver ó empalma una faca đde grandes dimen. siones» y la clava con insistencia en la región $\mathrm{H} 6 \mathrm{~B}$ del cuerpo de la desdichada. Cae ella, sin proferir un grito, en un charco de sangre: él la besa; se entrega á los guardias; le juzgan; el defensor le pinta como un Otelo forrado en Wérther; el tribunal le aplica cuatro 6 seis años, si no le absuelve... $y$ aqui no ha pasado nada, señores.

Porque la lenidad con esta clase de crimenes es grande. Sale bastante barato dar muerte á una mujer. Sería conveniente que costase algo más: tal-vez así lo pensarían mejor los celosos y los apasionados. La palabra pasión se toma aqui en un sentido vago y falso, como antes se tomaba la palabra honor. Tal pasiön es sólo capricho, sensualidad, vanidad mortificada. Para discernir cuál es pasión verdadera, si el asesino era realmente un maniático de pasión ó es sólo un violento que satisface su inclinación á la violencia, debiera averiguarse cuidadosamente la vida anterior, el comportamiento, el cómo se hubo siempre el matador con la víctima. Si el supuesto loco de amor es un vicioso, un mujeriego infiel, uno de los muchos que maltratan á la infeliz á quien acabarán por asesinar, la severidad de los jueces debería apoyarse en estos datos, la pena deberia ser fuerte $y$ máxima.

\section{A: Pardo Bazán, Emilia. (1915). "La vida contemporánea", en La ilustración artís- tica. Número 1740,302 \\ B: Pardo Bazán, Emilia. (1901). "La vida contemporánea", en La ilustración artís- tica. Número 1017, 410}

